\title{
Asset Pricing Implications of Benchmarking: A Two-Factor CAPM*
}

\author{
Juan-Pedro Gómez \\ and \\ Fernando Zapatero
}

This draft: July 2001

\begin{abstract}
In this paper we consider the equilibrium effects of an institutional investor whose performance is benchmarked to an index. In a partial equilibrium setting, the objective of the institutional investor is modeled as the maximization of expected utility (an increasing and concave function, in order to accommodate risk aversion) of final wealth minus a benchmark.

In equilibrium this optimal strategy gives rise to the two-beta CAPM in Brennan (1993): together with the market beta a new risk-factor (that we call active management risk) is brought into the analysis. This new beta is defined as the normalized (to the benchmark's variance) covariance between the asset excess return and the excess return of the market over the benchmark index.

Different to Brennan, the empirical test supports the model's predictions. The cross-section return on the active management risk is positive and significant especially after 1990, when institutional investors have become the representative agent of the market.
\end{abstract}

Keywords: asset pricing, benchmark portfolio, relative performance. JEL classification codes: G12, J33.

\footnotetext{
*An earlier version of this paper has circulated under the title "The Role of Institutional Investors in Equity Trading: An Explanation of the Home Bias Puzzle." We thank Michael Brennan, Michael Gavin, Eduardo Giménez, Debra Glassman, Ignacio Lobato, Jim Poterba, Richard Priestley and seminar participants at ITAM, CEMFI, the XXII Symposium of Economic Analysis, Barcelona, the III Financial Economics Meeting, Bilbao, the 1999 AFA Meetings in New York, Norwegian School of Management, Oslo and USC for comments and suggestions. Comments by the editor, Chris Adcock, and an anonymous referee helped to improve the paper. Existing errors are our sole responsibility. Address all correspondence to Juan-Pedro Gómez, Norwegian School of Management, Elias Smiths vei 15, N-1302 Sanvika, Norway. Phone: +47-6755 7398. Fax: +47-6755 7675.

$\dagger$ Norwegian School of Management, BI. E-mail: juan-pedro.gomez@bi.no

${ }^{\ddagger}$ FBE, Marshall School of Business, USC. E-mail: zapatero@usc.edu
} 


\section{Introduction}

The considerable increase in both the gross amount as well as the proportion of money managed by institutional investors observed in the last two decades (remarkably during the 1990s) has prompted a growing interest in the portfolio choice decisions of these investors and its effect on market prices. More specifically, we are interested in two well documented regularities, namely,

- the growing percentage of the stock market held by institutional investors (mainly mutual and pension funds) and

- the different target of individuals (households) and institutional investors in solving for their respective optimal portfolios.

The evolution of the stock funds total net $\operatorname{assets}^{1}$ as a percentage of the stock market capitalization might be useful to illustrate the increasing importance of institutional investors in equity trading. From 1984 to 1990, the percentage ranged between $5 \%$ and 8\%. After 1990 it has been increasing up to above $25 \%$ in December 1997. The number of (stock) funds in the sample observed an almost tenfold increase as of January, 1984. A parallel increase in the ratio of mutual funds to direct holdings of US equities (rising from a negligible amount in 1970 to about 25\% in 1990) has been reported by Sirri and Tufano (1993).

These figures seem to suggest that institutional investors (rather than households) should indeed be considered the "representative agent" in stock markets.

At this point, a question arises: Could it be argued that the (optimal portfolio choice) objective of institutional investors is different from that of households? Given the weight of institutional investors in the market a positive answer to the previous question will have to be followed by an analysis of its equilibrium implications.

It has been argued that "most mutual-fund managers actively buy and sell stocks in a bid to beat the market. Index-fund managers, called 'passive' investors, seek simply to match the performance of market indices, such as the Standard \& Poor's 500. " This behavior implies that, while households will be interested in maximization of final wealth, the results of institutional investors will be compared to some benchmark, usually some index of domestic securities.

A survey by Del Guercio and Tkac (1998) reports that $59 \%$ of mutual fund investors compared fund performance to that of an index. This percentage is lower

\footnotetext{
${ }^{1}$ The sample under consideration includes over $95 \%$ of the total US stock fund industry. Data provided by the Investment Company Institute (ICI). The ICI includes over 6,867 mutual funds and 447 close-end funds. Its mutual fund members represent more than 63 million individual shareholders and manage more than $\$ 4.8$ trillion. The Wilshire 5000 Index was used as a proxy for the US stock market capitalization value.

${ }^{2}$ The Wall Street Journal, January 28 of 1997.
} 
than that in the pension fund industry where virtually in all cases manager's portfolio performance is compared to an index. ${ }^{3}$

We therefore believe that institutional investors behave differently from households. Additionally, the former type of investor is gradually replacing the later as the "representative agent" in asset markets.

Roll (1992) shows, in a partial equilibrium framework, that the preferences assumed for a benchmarked investor (the representative institutional investor in our model) induce a discrepancy between her optimal portfolio and that of the standard risk-averse investor. Brennan (1993, 1995) studies the asset pricing implications of this alleged difference in a general equilibrium setting where institutional, benchmarked investors are present. He tests the model using monthly data from January 1931 through December 1991. The empirical evidence fails to support the model's predictions.

In this paper the model is tested on a monthly data sample from January 1973 through December 1997. Unlike in Brennan (1993), the results reported seem to support the objective function postulated for the representative institutional investor. Moreover, the empirical success of the model is shown to be robust to changes in the market and benchmark indexes.

The rest of the paper is organized as follows: Section 2 introduces a simple pure exchange, one-period closed economy. Agents can be either households or institutional investors. Assuming constant absolute risk-aversion utility functions, we compare the optimal portfolio of both types of investors. After that, a general equilibrium (CAPM) asset pricing equation is derived. Besides the standard systematic (market) risk-factor, a new factor is brought into the analysis: the active management risk. Our model predicts a positive expected reward on the active management risk.

Section 3 contains the empirical analysis of the paper. The predictions of the (extended) CAPM derived in Section 2 are tested on a monthly sample of 220 US assets, since January 1973 through December 1997. The S\&P 500 index is taken as the benchmark. Results confirm the model's predictions. Some robustness tests are performed in Section 3.3.1. Section 3.3.2 shows further evidence from the UK market. We close the paper with some conclusions.

\section{The model}

We derive a simple one-period equilibrium model. The framework is a pure exchange economy with only one consumption good. We first solve for the optimal portfolios of the agents in the economy. In the spirit of Merton (1973), we assume that the market capitalization value and market index portfolio are given. In equilibrium,

\footnotetext{
${ }^{3}$ Consider as well the usual practice observed in the mutual fund industry where funds advertise the record of years and the percentage by which they have outperformed "the market" represented by a benchmark index (typically the S\&P 500 Index in the case of American assets).
} 
supply equals demand and capital markets clear.

Investors only care about final wealth. The investment opportunity set consists of $N$ different assets. We will denote by $\tilde{r}=\left(\tilde{r}_{i}\right), i \in\{1,2, \ldots, N\}$ the vector of gross returns (in units of the consumption good). All assets are traded in a frictionless market where unlimited short selling is allowed. We assume $\tilde{r} \sim \mathcal{N}(\mu, \Omega)$ with $\Omega$ a positive definite matrix. $\mathbf{1} \in \Re^{N}$ will represent a column vector of ones. ${ }^{4}$ Let us denote $\omega \in \Re^{N}$ the vector of wealth weights invested in each security.

We will distinguish between two types of investors: absolute and benchmark investors. The representative absolute investor will choose her optimal (utility maximizing) portfolio in the standard mean-variance space. ${ }^{5}$ Besides the risky assets, the absolute investor can also invest in a risk-free asset with return $R$. Assuming a constant absolute risk aversion coefficient, $\pi>0$, the optimal portfolio for the absolute investor will be:

$$
\omega_{a}=\frac{1}{\pi} \Omega^{-1}(\mu-R \mathbf{1})
$$

Now consider the problem of a portfolio manager in a mutual or pension fund. This manager will be evaluated with respect to a given, exogenous benchmark portfolio $\phi \in \Re^{N}\left(\phi^{\prime} 1=1\right)$. For each expected excess return (above the benchmark's return) the manager will choose the portfolio with the minimum tracking error volatility. Let us denote $\underline{\omega}=(\omega-\phi)$ the net portfolio, that is, relative to the benchmark portfolio. For each $k \geq 0$ the manager will solve:

$$
\begin{array}{ll}
\min _{\underline{\omega}} & \frac{1}{2} \underline{\omega}^{\prime} \Omega \underline{\omega} \\
\text { s.t. } & \underline{\omega}^{\prime} \mu=k \\
& \underline{\omega}^{\prime} \mathbf{1}=0 .
\end{array}
$$

Roll (1992) and, more recently, Diacogiannis (1999) show that, when the benchmark portfolio $\phi$ is mean-variance inefficient, the locus that results from solving the benchmark investor's problem is suboptimal: for any target excess return, $k$, the minimum tracking error managed portfolio is dominated by feasible portfolios with higher average return and lower (total) volatility. As shown in Roll (1992), the net portfolio is independent of the choice of the benchmark and equal to

$$
\underline{\omega}(k)=\gamma(k) \Omega^{-1} \mu+\alpha(k) \Omega^{-1} \mathbf{1},
$$

where $\gamma$ and $\alpha$ represent the multipliers of the excess return and wealth constraints, respectively. Clearly, $\gamma$ represents the usual risk-return tradeoff: higher expected excess return (above the benchmark's return) comes to the cost of higher tracking error volatility. The case $k=0$ would correspond to an index fund.

\footnotetext{
${ }^{4}$ In general, bold characters will represent column vectors. Prime ( () will denote transpose.

${ }^{5}$ See, for instance, Roll (1977).
} 
Our benchmark investor will be interpreted as a portfolio manager with constant absolute risk aversion coefficient, $\pi>0$. We could assume different different risk aversion coefficients for the absolute and benchmark investors; however, none of the model's predictions would be affected. ${ }^{6}$ Thus, the manager's optimal portfolio will satisfy

$$
\gamma^{*}=\frac{1}{\pi}
$$

Finally, given (2) the optimal portfolio of the benchmark investor will be:

$$
\omega_{b}=\phi+\frac{1}{\pi} \Omega^{-1}(\mu-(A / C) \mathbf{1})
$$

with $A=\mathbf{1}^{\prime} \Omega^{-1} \mu$ and $C=\mathbf{1}^{\prime} \Omega^{-1} \mathbf{1}$; the ratio $A / C$ represents the expected return on the minimum variance portfolio of (purely) risky assets.

Let us denote $W_{a}\left(W_{b}\right)$ the initial wealth of the absolute (benchmark) investor. Aggregate demand $D$ will be:

$$
D=W_{a} \omega_{a}+W_{b} \omega_{b} .
$$

Risky assets are assumed to be in positive net supply. Let us introduce $S$, the (equilibrium) value of the aggregate market portfolio of risky assets and $x_{M} \in \Re^{N}$ $\left(x_{M}^{\prime} \mathbf{1}=1\right)$, the market portfolio vector of weights. We will assume that $S$ and $x_{M}$ are exogenously given. The asset market is assumed to be always in equilibrium. Market clearing requires $D=S x_{M}$. Replacing both portfolios with their values in equations (1) and (3), the market clearing condition becomes:

$$
W_{b} \phi+H^{-1} \Omega^{-1}(\mu-r \mathbf{1})=S x_{M} .
$$

In the later equation,

$$
H=\frac{\pi}{W_{a}+W_{b}}>0
$$

is the risk aversion coefficient (relative to the aggregate wealth in equilibrium);

$$
r=\frac{W_{a} R+W_{b} A / C}{W_{a}+W_{b}}
$$

represents the expected return on the "aggregate" minimum variance portfolio. Notice that, in the absence of benchmark investors $\left(W_{b}=0\right), r$ coincides with the risk-free rate, $R$, and the model collapses into the traditional one-factor CAPM.

Equation (4) can be rearranged as follows: ${ }^{7}$

\footnotetext{
${ }^{6}$ We thank an anonymous referee for suggesting this point.

${ }^{7}$ The vertical dots ( $\left.\vdots\right)$ denote column juxtaposition.
} 


$$
\begin{array}{ccc}
\mu-r \mathbf{1}=\left(\Omega x_{M} \vdots \Omega\left(\beta x_{M}-\phi\right)\right) & \times\left(\begin{array}{c}
H\left(S-\beta W_{b}\right) \\
H W_{b}
\end{array}\right), \\
(N \times 1) & (N \times 1 \vdots N \times 1) & (2 \times 1)
\end{array}
$$

for all $\beta \in \Re$. Equation (5) shows a general equilibrium relationship between stocks' expected (excess) return and stocks' covariance with both the market portfolio and the difference between the market and benchmark portfolios. The expected return on the covariance with the market index, $x_{M}$, is the standard CAPM result; however, portfolio managers care about relative performance. Therefore, not all market risk is systematic risk for these investors: only active management risk should be priced, i.e., the covariance with $\beta x_{M}-\phi{ }^{8}$

According to (5), the active management risk should arise for any benchmark index (efficient or not) non proportional to the market portfolio. If the optimal benchmark were endogenously determined by the model then any test on (5) would be a test exclusively on the asset pricing implications of the model; however, since the choice of the benchmark is exogenous, it will be a joint test on the model's predictions and the choice of the benchmark index. We will return to this issue in Section 3.

We introduce the following notation:

$$
\begin{aligned}
\mu_{M} & =x_{M}^{\prime}(\mu-r \mathbf{1}), \\
\mu_{\phi} & =\phi^{\prime}(\mu-r \mathbf{1}) .
\end{aligned}
$$

They represent the expected market and benchmark risk premia, respectively. Pre-multiplying both terms in equation (5) by $\left(x_{M} \vdots \beta x_{M}-\phi\right)^{\prime}$ we obtain

$$
\begin{array}{cc}
\left(\begin{array}{c}
\mu_{M} \\
\beta \mu_{M}-\mu_{\phi}
\end{array}\right)= & \Sigma(\beta) \times\left(\begin{array}{c}
H\left(S-\beta W_{b}\right) \\
H W_{b}
\end{array}\right), \\
(2 \times 1) & (2 \times 2)
\end{array}
$$

where

$$
\Sigma(\beta)=\left(x_{M}: \beta x_{M}-\phi\right)^{\prime} \Omega\left(x_{M}: \beta x_{M}-\phi\right)
$$

is the variance-covariance matrix of the market portfolio and the net portfolio. In the following section we perform the empirical analysis of the paper.

\footnotetext{
${ }^{8}$ Notice that the one-factor CAPM is embedded in the model: when $\phi=\beta x_{M}$, active management risk disappears as a differentiated risk factor. The standard CAPM result follows: only covariance with the market portfolio is priced.
} 


\section{Empirical analysis}

Equation (6) is the key to the risk premia in our model: how both risk factors are, on average, rewarded. In orther to specify the model and derive testable implications, $\beta$ is chosen such that both factors become "orthogonal"; that is $\hat{\beta}$ such that $\Sigma(\hat{\beta})$ is a diagonal matrix.

More specifically:

$$
x_{M}^{\prime} \Omega\left(\hat{\beta} x_{M}-\phi\right)=0,
$$

where,

$$
\hat{\beta}=\frac{x_{M}^{\prime} \Omega \phi}{x_{M}^{\prime} \Omega x_{M}} .
$$

The parameter $\hat{\beta}$ represents the covariance between the market portfolio and the benchmark over the market portfolio volatility: the slope of the regression of the benchmark on the market, i.e., the "unexplained" part of the benchmark portfolio. The portfolio $\hat{\beta} x_{M}-\phi$ is orthogonal to the market portfolio. It can be interpreted as a hedge portfolio in the terminology of Merton (1973). As a consequence, $\Omega\left(\hat{\beta} x_{M}-\phi\right)$ in equation (5) can be read as the conditional (on the market portfolio's return) covariance between the vector of gross returns and the return on the benchmark portfolio. ${ }^{9}$

Substituting $\hat{\beta}$ in (6):

$$
\begin{aligned}
\mu_{M} & =x_{M}^{\prime} \Omega x_{M} \times H\left(S-\hat{\beta} W_{b}\right), \\
\hat{\beta} \mu_{M}-\mu_{\phi} & =\phi^{\prime} \Omega \phi\left(1-\rho_{M \phi}^{2}\right) \times H W_{b},
\end{aligned}
$$

where $\rho_{M \phi}$ is the correlation coefficient between the market portfolio and the benchmark; $x_{M}^{\prime} \Omega x_{M}$ is the (unconditional) market volatility and $\phi^{\prime} \Omega \phi\left(1-\rho_{M \phi}^{2}\right)$ the conditional (on the market return) volatility of the benchmark portfolio.

According to (8), when we evaluate (6) at $\hat{\beta}$ the sign of the expected market risk premium, $\mu_{M}$, depends on the concrete value of the slope coefficient, $\hat{\beta}$. This means that the model cannot predict the sign of the unconditional market risk-premium. As a consequence, the mean-variance efficiency of the market portfolio is not an issue in our tests. ${ }^{10}$

On the other side, given the definition of $H$ and $w=W_{b} /\left(W_{a}+W_{b}\right)$, equation (9) becomes:

$$
\hat{\beta} \mu_{M}-\mu_{\phi}=\pi w \phi^{\prime} \Omega \phi\left(1-\rho_{M \phi}^{2}\right) .
$$

\footnotetext{
${ }^{9}$ We are grateful to the editor, Chris Adcock, for suggesting this interpretation.

${ }^{10}$ For tests on the mean-variance efficiency of the market portfolio see, for instance, Britten-Jones (1999), Gibbons, Ross and Shanken (1989) and Green (1986).
} 
Equation (10) shows that, in equilibrium, the expected active management risk premium is proportional $(\pi w)$ to the benchmark's volatility "weighted" by the complement to one of the (square) correlation between both portfolios. The higher the correlation, the lower the net market risk premium "per unit" of risk in equilibrium.

Given the assumptions of the model ( $\pi>0$ y $\Omega$ positive definite), the righthand side term in (10) is nonnegative; strictly positive for all $\rho_{M \phi}^{2}<1$. Notice that this result is independent of the value of $\hat{\beta}$.

As mentioned in Section 2, if the market portfolio and the benchmark are perfectly correlated $\left(\rho_{M \phi}^{2}=1\right)$ the active management risk cannot be distinguished from the (absolute) market risk and the model becomes the standard one-factor CAPM. In the other case, when such a risk exists $\left(\rho_{M \phi}^{2}<1\right)$ the corresponding risk premium is, on average, positive.

Equation (10) predicts that if the model is true and $\phi$ is the benchmark for portfolio evaluation, then the active management risk premium is, on average, positive. In this sense we say that empirical testing of equation (10) involves a "joint test" on the model's predictions and the benchmark choice.

\subsection{Description of data}

We will take the Standard \& Poor's S\&P 500 monthly index return as the return on the benchmark portfolio. ${ }^{11}$ The US Morgan Stanley Capital Indices (US-MSCI) index monthly return series will be taken as the market portfolio return. For the locally risk-free asset, the monthly return series of the three month Treasury Bill will be used. Our sample begins in January, 1973 and extends through December, 1997.

As risky assets, we selected the 220 US securities that have been in the S\&P 500 index without interruption from January, 1978 through December, 1997. Table I summarizes some descriptive statistics from the sample of selected risky assets compared to the S\&P 500 Index. We selected this sub-sample of assets in the S\&P 500 since we want to avoid the possible price effects associated with changes in the composition of the index. Any abnormal return captured in our tests cannot be explained by the assets being added or deleted from the benchmark index.

As in Adcock and Clark (1999) we will express the two-factor CAPM as a function of the conditonal moments. Let us denote $R_{M}\left(R_{S \& P}\right)$ the market (benchmark) risk premium. Following Errunza and Losq (1985), the benchmark is regressed on the market portfolio. The residuals of this regression (multiplied by minus one, $-e_{S \& P}$ ) and the hedge portfolio $\hat{\beta} x_{M}-\phi$ (orthogonal to the market portfolio by construction) are numerically identical. Therefore, provided that the model is correct:

\footnotetext{
${ }^{11}$ The S\&P 500 Index consists of 500 stocks chosen for market size, liquidity, and industry group representation. It is a market-value weighted index, with each stock's weight in the Index proportional to its market value. In January, 1998, industrials accounted for $76 \%$ of the companies in the Index; utilities $7.4 \%$, financials $14.2 \%$ and transportation $2 \%$. Over $90 \%$ of the stocks in the Index are traded on the NYSE.
} 


$$
R^{i}=\beta_{0}^{i} \mathbf{1}+\beta_{M}^{i} R_{M}-\beta_{S \& P}^{i} e_{S \& P}+\epsilon^{i},
$$

for every asset $i$. $\beta_{S \& P}^{i}$ and $\beta_{M}^{i}$ are, respectively, the benchmark (conditional covariance) and market (unconditional covariance) betas. The residual terms $\epsilon$ are assumed to be i.i.d. Betas, variances and covariances are stationary over time.

\subsection{Methodology}

We follow Fama and MacBeth (1973). Testing (10) implies a two-step process: first, estimating the market and benchmark betas according to equation (11); then, running cross-section regressions of stock's expected returns on the estimated betas:

$$
R_{t}=\gamma_{0, t} \mathbf{1}+\gamma_{M, t} \hat{\beta}_{M, t-1}+\gamma_{S \& P, t} \hat{\beta}_{S \& P, t-1}+\eta_{t}
$$

for each month $t$. The (monthly) time series means of $\tilde{\gamma}_{M}$ and $\tilde{\gamma}_{S \& P}$ will then be used to test (H1) whether the market, on average, rewards both market and active management risk and (H2) on average, the active management risk premium is positive.

The sample (1973-97) is divided in three periods: (1) January, 1973 to December, 1987, (2) January, 1978 to December, 1992 and (3) January, 1983 to December, 1997.

Within each period the sample is again divided into three more subperiods, each including five consecutive years. The first five years will constitute the portfolio formation period; the next five years will be the initial estimation period. The testing period will include the last five years. Table II summarizes the whole structure of divisions and subdivisions of the data sample.

In each portfolio formation period, equilibrium asset returns are assumed to satisfy (11). In the first place, ordinary least squares (OLS) regressions will be run for the 220 US risky assets with excess returns as dependent variables and market excess return and residual series as regressors.

To obtain more precise estimates of the betas, assets will be grouped into portfolios. Assuming that the measurement errors are uncorrelated across assets, the variance of the measurement errors for the portfolio betas would approach zero as the number of assets in each portfolio increases. However, there is a tradeoff between precision and efficiency involved in this process. This issue is especially relevant in our test since neither the number of assets nor the time-horizon of the sample are too large.

Every portfolio formation period assets are sorted according to their estimated market index beta. Then, we will calculate the difference between the first and the last market beta and divide it by 10. The ranked assets are then grouped into portfolios. Every time an asset is added to a portfolio the median market beta of the portfolio is calculated. If the next asset's market beta does not diverge from the median more than half the benchmark distance previously calculated, then the asset 
is included into the portfolio. Otherwise, the actual portfolio is closed and the new asset is included in the next portfolio. This process is repeated until every asset is included in some portfolio. Assets are then simply averaged within each portfolio.

Within every portfolio formation period, new OLS regressions will be run with portfolio mean returns as the new dependent variables. The resulting portfolio market and benchmark (residuals) estimated betas, together with the corresponding standard errors, are presented in Table III. We also include intercept estimates and standard errors. The resulting portfolios in each period are 11, 9 and 10, respectively. As predicted, the estimated benchmark betas, $\hat{\beta}_{S \& P}$, are all negative and, in most of the cases (especially in the last two periods), highly significant. All the estimated market betas are positive and virtually all statistically highly significant.

Within every initial portfolio estimation subperiod, regressions are run keeping the same portfolios constructed in the portfolio formation period but now using data from the next 5 years. Thereafter, portfolio betas are themselves updated yearly through the testing period. For instance, in the first testing period (1983-87) the 11 portfolio betas will be recomputed yearly using monthly returns from 1978 through 1982 to 1986. These betas will be the independent variables in regression (12): Each month, portfolios' returns are (cross-section) regressed on the market and benchmark betas estimated from January, 1978 through December of the previous year.

This three-stage process is repeated in Period 2 and Period 3. This allows portfolios to be rebalanced every 5 years, at each portfolio formation period. The time series means of the monthly regressions slopes $\left(\overline{\hat{\gamma}}_{0, t}, \overline{\hat{\gamma}}_{M, t}\right.$ and $\left.\overline{\hat{\gamma}}_{S \& P, t}\right)$ from January, 1983 through December, 1997 will provide standard tests on hypothesis H1 and H2.

\subsection{Analysis of the results}

Table IV.A presents the average slope coefficients for different time intervals from regression (12) in the testing period. Standard deviations and t-values for each of the average slopes are also reported.

When considering the whole testing period, 1983-1997, both market and active management risk are positively rewarded and statistically different from zero at the $10 \%$ level. It is more interesting, though, to see the value of these statistics when the sample is split in two subperiods: From January, 1983 to December, 1991 and from January, 1992 to December, 1997. In the first subperiod, neither the absolute nor the net market risk premia are significantly different from zero. In the second, both risk-factors are positively rewarded and statistically different from zero at $5 \%$, supporting hypothesis $\mathrm{H} 1$ and $\mathrm{H} 2$.

As supplementary evidence in favor of $\mathrm{H} 2$, Table $\mathrm{V}$ presents the average slopes from regression (12), together with t-values, computed yearly from January 1990 through December 1997. The average slope coefficient for the active management risk, $\overline{\hat{\gamma}}_{S \& P, t}$, is statistically significant at $5 \%$, from December 1992 onwards. The average slope presents a sixfold increase from 1991 to 1992. Then, it gradually decreases along 
the years. According to the ICI sample of stock funds (which includes over $95 \%$ of the total US stock fund industry), the total net assets in the stock fund industry rose $67 \%$ in 1991. After 1991, the amount of net assets have increased (always at smaller percentages) along the years. We do not have data concerning the pension fund industry.

\subsubsection{Results with alternative market and benchmark indices}

Panel B in table IV reports the results of performing the same tests as in Panel A after replacing US-MSCI with the US-Datastream as the market portfolio index. The S\&P 500 will remain as the benchmark portfolio.

This exercise aims to test how robust our results are to the choice of the market index. Table IV.B shows that the average return on the (absolute) market risk is not significant at any level, no matter the time interval considered. This result coincides with other results in the empirical literature on CAPM testing, such as Chen, Roll and Ross (1986) and Fama and French (1992): The market-beta has no "explanatory power" in the cross-section regressions. The expected return on the active management risk is positive and significant (at the 10\% level). It is interesting to see that all the significance in the test comes from the last years in the sample.

Therefore, the market risk premium is shown to be very sensitive to the market index choice while the active management risk is (partially) robust to the change.

Panel C in tables IV shows a symmetric exercise. Now, US-MSCI will remain as the market index while the S\&P 500 will be replaced with the Dow Jones Industrials (DJI) index. The three indices are highly correlated among themselves. This new exercise purports to empirically test whether the results reported in Panel A could be replicated by any pair of (highly correlated) market index proxies. If the results reported in Panel A did not qualitatively change, this would evidence that they are to a large extent spurious: The positive expected reward on the active management risk would not necessarily represent empirical support for the theoretical model in Section 2.

Table IV.C shows that the average return on the net market risk (with respect to the DJI) is non-significant and even negative in some time intervals. The average return on the market risk is positive (though non-significant) when considering the whole testing period, 1983-1997.

Therefore, when the S\&P 500 is replaced with the DJI the data fails to support hypothesis H1-H2. We take this as evidence in favor of our model. Both indices are common proxies for market performance and thus, highly correlated. However, only the S\&P 500 (clearly the dominant domestic index for management compensation in the US) is priced as active management risk. 


\subsubsection{Results from the test on UK stocks}

As a complementary robustness test we replicate the original exercise on 64 stocks trading in the London Stock Exchange. As a locally risk-free rate, the monthly return series of the three months interbank-loans rate will be used. ${ }^{12}$ The FTSE 100 monthly index return is taken as the return on the benchmark portfolio. Finally, the UK-Datastream index will be used as the market portfolio. ${ }^{13}$ Our sample expands from January, 1980 through December, 1996.

During the first portfolio formation period (January, 1980 through December, 1982) 10 portfolios were formed. A total of 11 portfolios were constructed during the second formation period (January, 1983 through December, 1987). The total testing period extends from January, 1988 through December, 1996.

The results from the test are shown in Table VI. The total sample results show little support in favor of the model: both the market and, more importantly, the benchmark average risk-premia are non-significant. However, it is interesting to notice how the sign on the later changes from the first to the second half of the testing period. In the last four years of the sample (arguably when the trading volume by institutional investors should be higher) the average risk-premium on the benchmark beta $\left(\overline{\hat{\gamma}}_{F T S E, t}\right)$ is positive (as predicted by the model) and significant at the $10 \%$.

We interpret this result as (partial) evidence in favor of the model. We believe that the results from the UK stocks are not as conclusive as the evidence documented for the US stocks since, to our knowledge, there is no such a pervasive consensus on the FTSE 100 as the benchmark index for the compensation of British fund managers (compared with the S \& P 500 in the American case).

\section{Conclusions}

In the spirit of Brennan (1993) we consider the optimal strategy of an institutional investor that tries to maximize the surplus of final wealth over a benchmark. In equilibrium this gives rise to a two factor CAPM where the first factor is the traditional market risk component and the second factor represents the risk of deviating from the benchmark. We extend Brennan's test up to December 1997. The benchmark we use is the S\&P 500 Index and the securities are all 220 stocks that have been in the S\&P 500 during the period considered.

The test confirms the model's hypothesis, especially in the last part of our time sample as it should be expected since it represents historically the peak in market participation of institutional investors. This result is shown to be robust to changes in the market and benchmark indexes. Additional evidence is presented on UK stocks.

Other equilibrium effects of this phenomenum are left for future research.

\footnotetext{
${ }^{12}$ We prefer this rate over the UK T-bill series since the later is a rather illiquid market.

${ }^{13}$ The time series correlation of both indexes is $97.22 \%$.
} 


\section{References}

Adcock, C.J. and E.A. Clark (1999) "Beta lives-Some statistical perspectives on the capital asset pricing model," European Journal of Finance 5, 213-224.

Brennan, M. (1993) "Agency and asset pricing," Working Paper no. 6-93. UCLAAnderson Graduate School of Management.

Brennan, M. (1995) "The individual investor," Journal of Financial Research 1, $59-74$.

Britten-Jones, M. (1999) "The sampling error in estimates of mean-variance efficient portfolio weights," Journal of Finance 54, 655-671.

Chen, N., R. Roll and S Ross (1986) "Economic forces and the stock market," Journal of Business 59, 383-403.

Del Guercio, D. and P. Tkac (1998) "The determinants of the low of funds of managed portfolios: Mutual funds versus pension funds" Mimeo, University of Oregon.

Diacogiannis, G.P. (1999) "A three-dimensional risk-return relationship based upon the inefficiency of a portfolio: derivation and implications," European Journal of Finance 5, 225-235.

Errunza, V. and E. Losq (1985) "International asset pricing under mild segmentation: theory and test," Journal of Finance 40, 105-123.

Fama, E. and J. MacBeth (1973) "Risk, return and equilibrium: Empirical tests," Journal of Political Economy 81, 607-636.

Fama, E. and K. French (1992) "The cross-section expected stock returns," Journal of Finance 47, 427-465.

Gibbons, M.R., S.A. Ross and J. Shanken (1989) "A test of the efficiency of a given portfolio," Econometrica 57, 1121-1152.

Green, R.C. (1986) "Benchmark portfolio inefficiency and deviations from the security market line," Journal of Finance 41, 295-312.

Merton , R. (1973) "An intertemporal capital asset pricing model," Econometrica $41,867-887$. 
Roll, R. (1977) "A critique of the asset pricing theory's tests: Part 1: on the past and potential testability of the theory," Journal of Financial Economics, 4, 129-176.

Roll, R. (1992) "A mean/variance analysis of tracking error," Journal of Portfolio Management Summer, 13-22.

Sirri, E.R. and P. Tufano (1993) "Competition and change in the mutual fund industry," Financial Services: Perspectives and Challenges, Samuel L. Hayes Ed. 
TABLE I

Risky Assets Sample and S\&P 500 Statistics (millions of US dollars)

\begin{tabular}{lrr}
\hline \hline & Assets sample & \multicolumn{1}{c}{ S\&P 500 } \\
\cline { 2 - 3 } Total Market value & $4,528 \times 10^{3}$ & $7,657 \times 10^{3}$ \\
Mean Market Value & 21,060 & 15,313 \\
Median Market Value & 8,805 & 6,905 \\
Largest Company's Market Value & 243,300 & 253,636 \\
Smallest Company's Market Value & 535 & 430 \\
\hline \hline Note: Data as of January 1998. & &
\end{tabular}

TABLE II

Portfolio Formation, Initial Estimation and Testing Periods

\begin{tabular}{lccc}
\hline \hline & \multicolumn{3}{c}{ Periods } \\
\cline { 2 - 4 } & 1 & 2 & 3 \\
\hline Porfolio formation period & $1973-77$ & $1978-82$ & $1983-87$ \\
Initial estimation period & $1978-82$ & $1983-87$ & $1988-92$ \\
Testing period & $1983-87$ & $1988-92$ & $1993-97$ \\
\hline \hline
\end{tabular}




\section{TABLE III}

\section{Estimated intercept, market and benchmark betas}

$$
\tilde{R}_{t}=\beta_{0}+\tilde{R}_{M, t} \beta_{M}-\tilde{e}_{S \& P, t} \beta_{S \& P}+\tilde{\epsilon}_{t}
$$

Every portfolio formation period, equilibrium asset returns are assumed to satisfy the equation above. In the first place, ordinary least squares (OLS) regressions will be run for the 220 US risky assets with excess returns as dependent variables and market excess return and residual series as regressors. Ater that, assets are sorted according to their estimated market index beta. Then, we will calculate the difference between the first and the last market beta and divide it by 10. Under the assumption of a uniform distribution of estimated marked betas, this distance would yield 10 portfolios of 22 assets each one. It represents a benchmark dispersion measure.

The ranked assets are then gathered into portfolios. Every time an asset is added to a portfolio the median market beta of the portfolio is calculated. If the next asset's market beta does not diverge from the median more than half the benchmark distance previouly calulated, then the asset is included into the portfolio. Otherwise, the actual portfolio is closed and the new asset is included in the next portfolio. This process is repeated until every asset is included in some portfolio. Assets are then simply averaged within each portfolio. New OLS regressions are run with portfolio mean returns as the new dependent variables.

US Morgan Stanley Capital Index is used as the market index. S\&P 500 is the benchmark (s.e. stands for standard error).

\begin{tabular}{|c|c|c|c|c|c|c|c|c|c|c|c|}
\hline STATISTIC & 1 & 2 & 3 & 4 & 5 & 6 & 7 & 8 & 9 & 10 & 11 \\
\hline & \multicolumn{11}{|c|}{ Portfolio Formation Period 1973-77 } \\
\hline$\hat{\beta}_{0}$ & 0.015 & 0.004 & 0.003 & 0.006 & 0.011 & 0.01 & 0.015 & 0.01 & 0.026 & 0.024 & 0.033 \\
\hline s.e. & 0.013 & 0.002 & 0.002 & 0.002 & 0.003 & 0.003 & 0.006 & 0.006 & 0.011 & 0.019 & 0.014 \\
\hline$\hat{\beta}_{M}$ & 0.246 & 0.673 & 0.902 & 1.139 & 1.317 & 1.468 & 1.658 & 1.826 & 1.968 & 2.173 & 2.331 \\
\hline s.e. & 0.243 & 0.044 & 0.04 & 0.038 & 0.059 & 0.063 & 0.125 & 0.123 & 0.22 & 0.364 & 0.28 \\
\hline$\hat{\beta}_{S \& P}$ & -0.812 & -0.704 & -0.856 & -0.814 & -1.111 & -1.109 & -0.753 & -1.382 & -3.502 & -0.767 & -1.611 \\
\hline \multirow[t]{2}{*}{ s.e. } & 1.032 & 0.185 & 0.169 & 0.16 & 0.252 & 0.266 & 0.532 & 0.522 & 0.931 & 1.542 & 1.189 \\
\hline & \multicolumn{11}{|c|}{ Portfolio Formation Period 1978-82 } \\
\hline$\hat{\beta}_{0}$ & -0.006 & 0.001 & 0.002 & 0.003 & 0.007 & 0.011 & 0.019 & 0.02 & 0.022 & & \\
\hline s.e. & 0.004 & 0.003 & 0.003 & 0.002 & 0.002 & 0.003 & 0.004 & 0.006 & 0.01 & & \\
\hline$\hat{\beta}_{M}$ & 0.287 & 0.618 & 0.858 & 1.069 & 1.268 & 1.48 & 1.66 & 1.867 & 2.124 & .. & $\ldots$ \\
\hline s.e. & 0.094 & 0.074 & 0.06 & 0.042 & 0.052 & 0.068 & 0.094 & 0.131 & 0.22 & $\ldots$ & $\cdots$ \\
\hline$\hat{\beta}_{S \& P}$ & -0.157 & -1.002 & -0.793 & -1.042 & -1.128 & -1.182 & -1.748 & -1.545 & -1.347 & & \\
\hline \multirow[t]{2}{*}{ s.e. } & 0.318 & 0.249 & 0.202 & 0.143 & 0.175 & 0.23 & 0.318 & 0.443 & 0.743 & $\ldots$ & $\ldots$ \\
\hline & \multicolumn{11}{|c|}{ Portfolio Formation Period 1983-87 } \\
\hline$\hat{\beta}_{0}$ & 0.003 & -0.001 & 0.005 & 0.001 & 0.001 & 0.001 & 0.000 & 0.001 & 0.01 & 0.003 & \\
\hline s.e. & 0.005 & 0.003 & 0.002 & 0.001 & 0.002 & 0.002 & 0.003 & 0.009 & 0.01 & 0.021 & $\ldots$ \\
\hline$\hat{\beta}_{M}$ & 0.312 & 0.491 & 0.706 & 0.87 & 1.072 & 1.258 & 1.406 & 1.54 & 1.725 & 1.976 & \\
\hline s.e. & 0.104 & 0.066 & 0.042 & 0.024 & 0.034 & 0.046 & 0.063 & 0.183 & 0.192 & 0.405 & \\
\hline$\hat{\beta}_{S \& P}$ & -0.054 & -0.109 & -0.631 & -0.991 & -1.132 & -1.144 & -1.233 & -0.721 & -2.391 & -0.128 & \\
\hline s.e. & 0.41 & 0.259 & 0.164 & 0.096 & 0.133 & 0.180 & 0.25 & 0.724 & 0.756 & 1.599 & $\cdots$ \\
\hline
\end{tabular}


TABLE IV

US stocks: Average slope coefficients $(\times 100)$.

$$
\tilde{R}_{t}=\tilde{\gamma}_{0, t}+\tilde{\gamma}_{M, t} \hat{\beta}_{M, t-1}+\tilde{\gamma}_{S \& P, t} \hat{\beta}_{S \& P, t-1}+\tilde{\eta}_{t}
$$

Panel A: US-MSCI as market index and S\&P 500 as benchmark. Panel B: US-Datastream as market index and S\&P 500 as benchmark. Panel C: US-MSCI as market index and Dow Jones Industrials as benchmark ( $s$ stands for standard deviation, $t$ stands for t-value).

See the text for details.

\begin{tabular}{|c|c|c|c|c|c|c|c|c|c|}
\hline \multirow[b]{2}{*}{ PERIOD } & \multicolumn{9}{|c|}{ StATISTIC } \\
\hline & $\overline{\hat{\gamma}}_{0, t}$ & $\overline{\hat{\gamma}}_{M, t}$ & $\overline{\hat{\gamma}}_{S \& P, t}$ & $s\left(\hat{\gamma}_{0, t}\right)$ & $s\left(\hat{\gamma}_{M, t}\right)$ & $s\left(\hat{\gamma}_{S \& P, t}\right)$ & $t\left(\overline{\hat{\gamma}}_{0, t}\right)$ & $t\left(\overline{\hat{\gamma}}_{M, t}\right)$ & $t\left(\overline{\hat{\gamma}}_{S \& P, t}\right)$ \\
\hline \multicolumn{10}{|l|}{ Panel A } \\
\hline 1983-1997 & -0.03 & 2.41 & 1.78 & 0.08 & 0.2 & 0.13 & -0.04 & 1.65 & 1.80 \\
\hline 1983-1991 & 1.09 & -0.28 & 0.36 & 0.09 & 0.16 & 0.09 & 1.3 & -0.17 & 0.41 \\
\hline 1992-1997 & -1.7 & 6.44 & 3.91 & 0.07 & 0.23 & 0.17 & -1.97 & 2.34 & 1.87 \\
\hline \multicolumn{10}{|l|}{ Panel B } \\
\hline 1983-1997 & 0.59 & 0.04 & 0.07 & 0.06 & 0.07 & 0.01 & 1.35 & 0.09 & 1.3 \\
\hline 1983-1991 & 0.78 & -0.35 & 0.03 & 0.062 & 0.071 & 0.006 & 1.3 & -0.5 & 0.44 \\
\hline 1992-1997 & 0.3 & 0.64 & 0.14 & 0.05 & 0.05 & 0.01 & 0.5 & 0.1 & 1.3 \\
\hline \multicolumn{10}{|l|}{ Panel C } \\
\hline 1983-1997 & 0.37 & 0.2 & -0.22 & 0.07 & 0.11 & 0.07 & 0.7 & 0.26 & -0.43 \\
\hline 1983-1991 & 1.01 & -0.79 & -0.52 & 0.08 & 0.12 & 0.08 & 1.43 & -0.72 & -0.71 \\
\hline 1992-1997 & -0.2 & 1.12 & 0.06 & 0.08 & 0.12 & 0.07 & -0.28 & 1.04 & 0.09 \\
\hline
\end{tabular}


TABLE V

US stocks: Average slope coefficients $(\times 100)$.

$\tilde{R}_{t}=\tilde{\gamma}_{0, t}+\tilde{\gamma}_{M, t} \hat{\beta}_{M, t-1}+\tilde{\gamma}_{S \& P, t} \hat{\beta}_{S \& P, t-1}+\tilde{\eta}_{t}$

\begin{tabular}{lrrrrrrrr}
\multicolumn{8}{c}{$R_{t}=\tilde{\gamma}_{0, t}+\tilde{\gamma}_{M, t} \beta_{M, t-1}+\tilde{\gamma}_{S \& P, t} \beta_{S \& P, t-1}+\tilde{\eta}_{t}$} \\
\hline \hline \multirow{8}{*}{ StATISTIC } & 1990 & 1991 & 1992 & 1993 & 1994 & 1995 & 1996 & 1997 \\
\cline { 2 - 9 } & & & & & & & & \\
$\overline{\hat{\gamma}}_{0, t}$ & 1.13 & -0.11 & -2.78 & -2.18 & -1.96 & -1.42 & -1.2 & -1.3 \\
t-value & 0.28 & -0.04 & -1.28 & -1.32 & -1.46 & -1.25 & -1.3 & -1.47 \\
$\overline{\hat{\gamma}}_{M, t}$ & -3.69 & 1.02 & 10.91 & 8.67 & 7.15 & 6.2 & 5.72 & 5.08 \\
t-value & -0.41 & 0.19 & 1.69 & 1.79 & 1.83 & 1.9 & 2.03 & 2.06 \\
$\overline{\hat{\gamma}}_{S \& P, t}$ & -0.82 & 1.33 & 8.38 & 6.33 & 5.26 & 4.61 & 4.11 & 3.27 \\
t-value & -0.18 & 0.47 & 1.9 & 1.89 & 1.95 & 2.04 & 2.12 & 1.9 \\
\hline \hline
\end{tabular}

TABLE VI

UK stocks: Average slope coefficients $(\times 100)$.

$\tilde{R}_{t}=\tilde{\gamma}_{0, t}+\tilde{\gamma}_{M, t} \hat{\beta}_{M, t-1}+\tilde{\gamma}_{F T S E, t} \hat{\beta}_{S \& P, t-1}+\tilde{\eta}_{t}$

UK-Datastream as market index and FTSE 100 as benchmark ( $s$ stands for standard deviation, $t$ stands for t-value). See the text for details.

\begin{tabular}{|c|c|c|c|c|c|c|c|c|c|}
\hline \multirow[b]{2}{*}{ PERIOD } & \multicolumn{9}{|c|}{ STATISTIC } \\
\hline & $\overline{\hat{\gamma}}_{0, t}$ & $\overline{\hat{\gamma}}_{M, t}$ & $\overline{\hat{\gamma}}_{F T S E, t}$ & $s\left(\hat{\gamma}_{0, t}\right)$ & $s\left(\hat{\gamma}_{M, t}\right)$ & $s\left(\hat{\gamma}_{F T S E, t}\right)$ & $t\left(\overline{\hat{\gamma}}_{0, t}\right)$ & $t\left(\overline{\hat{\gamma}}_{M, t}\right)$ & $t\left(\overline{\hat{\gamma}}_{F T S E, t}\right)$ \\
\hline 1988-1996 & 0.82 & -0.75 & -0.30 & 0.15 & 0.14 & 0.04 & 0.59 & -0.56 & -0.70 \\
\hline 1988-1992 & 1.61 & -1.72 & -0.95 & 0.17 & 0.17 & 0.06 & 0.72 & -0.80 & -1.33 \\
\hline 1993-1996 & -0.17 & 0.47 & 0.51 & 0.10 & 0.09 & 0.03 & -0.11 & 0.34 & 1.39 \\
\hline
\end{tabular}

